\title{
LA INICITIVA DE FIGO PARA LA PREVENCIÓN DEL ABORTO INSEGURO
}

\begin{abstract}
ABORTO es una palabra que despierta grandes emociones y acaloradas discusiones de personas que parecen en posiciones irreconciliables, lo que hace que la mayoría evite mencionarla. Hablemos de él o no, el aborto existe, es un drama personal para millones de mujeres y en países en que es ilegal y se practica en la clandestinidad en condiciones precarias, puede ser una causa muy importante de mortalidad y morbilidad materna. En África, al sur del Sahara, cerca de una de cada 120 mujeres que se provoca un aborto muere en ese proceso y una alta proporción tiene secuelas que la limitan el resto de su vida. Infelizmente ningún problema social se resuelve ignorándolo. Solo se consigue reducirlo reconociendo que existe, evaluando sus causas e identificando acciones que puedan corregirlas.
\end{abstract}

Todas estas razones: su invisibilidad, su importancia como causa de enfermedad y muerte, y que se conoce cuáles intervenciones son eficientes para reducir los abortos, llevó a la Federación Internacional de Ginecología y Obstetricia (FIGO) a crear un Grupo de Trabajo sobre Prevención del Aborto Inseguro, que me dieron la misión de coordinar. La Presidenta de FIGO envió una carta a todas las sociedades afiliadas convidándolas a participar en esta iniciativa. El Grupo de Trabajo le dio seguimiento, con énfasis en los países con tasas elevadas de aborto inseguro o de aborto provocado, aunque fuera legal y sin grandes riesgos para la mujer, como es el caso de los países de la antigua Unión Soviética y sus aliados. La idea es que un aborto es una experiencia más o menos traumática para la mujer y siempre significa la pérdida de un embrión o feto, y por lo tanto, se debe evitar.

Las sociedades que aceptaran participar debían designar a uno de sus miembros como "punto focal" para la iniciativa y realizar un análisis de la situación del aborto en el país. Este análisis debía incluir su magnitud, sus consecuencias, los factores determinantes y la calidad de la atención a las mujeres con complicaciones de aborto, incluyendo la información y servicios de anticoncepción postaborto. El objetivo del análisis es de identificar los puntos susceptibles de intervenciones que puedan reducir los embarazos no deseados y los abortos provocados y sus consecuencias. A partir de ese diagnóstico, se deben proponer las acciones que permitan corregir los problemas identificados.

Es obvio que si queremos que esas acciones realmente se pongan en práctica las Sociedades de Ginecología y Obstetricia no pueden actuar aisladamente. Se hace necesaria la participación activa de otros actores sociales, fundamentalmente los gobiernos, a través del Ministerio de Salud y otras agencia del sector público; de organizaciones no gubernamentales locales e internacionales, como las asociaciones afiliadas a la Federación Internacional de Planificación Familiar (IPPF), y organismos internacionales como la Organización Mundial de Salud y el UNFPA.

Idealmente estos otros actores deben poder participar desde la preparación del análisis de la situación, pero es más necesario que participen en la definición y ejecución del plan de acción, lo que los compromete más a colaborar con su puesta en práctica.

FIGO no tiene ninguna estrategia definida de plan de acción. Este tiene que ser definido en cada país de acuerdo con los problemas identificados por el análisis de la situación que sean susceptibles de corrección, de acuerdo con la cultura y sobre todo, respetando las leyes de cada país.

En muchos casos las acciones propuestas coinciden, total o parcialmente, con programas ya existentes, todavía no aplicados o ya en marcha. En esos casos se trataría de acelerar el proceso de ejecución de las acciones, utilizando el peso del prestigio de la Sociedad de Ginecología y Obstetricia y la colaboración de sus miembros. Hay que recordar que la mayoría de las acciones de salud que afectan a la mujer dependen de la participación de ginecólogos y obstetras. Como dijo el ex-presiden- 
te de FIGO, Mahmoud Fathalla, nosotros podemos ser tanto parte del problema como parte de la solución. El liderazgo de la Sociedad debe permitir que seamos lo segundo. El proyecto de FIGO puede contribuir, además, a comprometer la colaboración de los otros actores sociales convidados a participar en esta iniciativa.

No importa que en estos casos la iniciativa de FIGO pierda su identidad y aparezca como un programa de otros organismos, gubernamentales o no. Lo que interesa es que la iniciativa pueda contribuir a que menos mujeres se embaracen cuando les parezca absolutamente intolerable tener un hijo, a que haya menos abortos y menos consecuencias negativas de ese proceso.

Hasta este momento, primera semana de Julio de 2008, 54 países están participando en esta iniciativa: nueve en América del Sur; nueve en América Central, México y el Caribe, siete en África Occidental y Central, siete en África Oriental, Central y del Sur; seis en Norte de África y Mediterráneo Oriental, ocho en el Sur y Sudeste Asiático y ocho en Europa Oriental y Central (incluyendo un país de Asia central).

La coordinación de una iniciativa de esas dimensiones mundiales sólo es posible gracias a la capacidad y dedicación de un grupo de Coordinadores Regionales, totalmente convencidos del valor de esta iniciativa para mejorar la vida de las mujeres y disminuir los abortos en sus respectivas regiones. A estos 54 países incluidos en la proposición inicial, se sumaron tres países con tasas medias de aborto provocado y sin aborto inseguro: EEUU, Canadá y Suecia. El problema de estos últimos países es que mantienen una tasa de aborto algo por encima de 20 por mil mujeres en edad fértil, tres veces más que en países como Holanda o Suiza y sin mejora perceptible en la última década. EEUU enfrenta además un elevado porcentaje de embarazos que no son planeados: cerca de $50 \%$ en la población total y casi dos tercios entre adolescentes. Algo parecido se observa en Canadá y en Suecia. Este último país tiene la más alta tasa de abortos por mil mujeres de 25 a 49 años de Europa Occidental y reconoce que sus programas de educación en sexualidad se han debilitado en los últimos años.

La Sociedad Chilena de Ginecología y Obstetricia fue una de las primeras que respondió positi- vamente a la invitación de FIGO y también estuvo entre las primeras en completar un análisis de la situación del aborto en Chile, en base a los datos disponibles. Esta información fue compartida con colegas de los otros países de América del Sur en un Taller Regional realizado en Lima, Perú, los días 23 y 24 de Junio pasado. Fue notorio el contraste entre la situación de Chile y la mayor parte de los otros países. Chile está mucho más próximo a la situación de los EEUU que a la de muchos países de nuestra región, lo que tal vez se explica por la larga historia de acceso amplio a anticoncepción de alta eficacia y a las buenas condiciones sanitarias generales de nuestro país. Hay, sin embargo, muchos aspectos en que es posible mejorar para poder reducir los abortos a un mínimo, hasta llegar a los niveles de Holanda y de Suiza.

Así mismo, hay fuertes evidencias de que muy pocas mujeres han muerto por aborto en Chile en los últimos años y no parece ser un problema que pueda ser catalogado como de "salud pública". Hay que pensar, sin embargo, que para cada una de esas mujeres, casi siempre jóvenes, que murieron inútilmente, y para sus familias, cada una de esas muertes es un drama que podría haber sido evitado. Analizar cada caso y aprender de ellos para que nadie muera por aborto en Chile en los próximos años, acercándonos a Suecia y otros países que hace años no registran muertes por esta causa, es un objetivo por lo menos tan prioritario como reducir las muertes maternas por hipertensión y preeclampsia o por cualquier otra causa.

La tarea de elaborar un plan de acción que permita alcanzar esos objetivos está siendo liderada por la Sociedad Chilena de Ginecología y Obstetricia, en colaboración con el Ministerio de Salud y otras instituciones nacionales e internacionales, como la OPS. Obviamente que esta no es una tarea que los ginecólogos y obstetras podamos realizar solos, pero nuestro papel como médicos de las mujeres, es tan importante, que la participación de todos los colegas en la ejecución de ese plan es una condición indispensable para alcanzar esos objetivos.

Dr Aníbal Faúndes. Coordinador del Grupo de Trabajo. Prevención del Aborto Inseguro, FIGO. 